\title{
Маркеры метакоммуникации в разных социальных ролях говорящего: на материале прагматического аннотирования корпусных данных
}

\author{
Т. И. Попова \\ Санкт-Петербургский государственный университет \\ tipopova13@gmail.com
}

\section{Аннотация}

Прагматическое аннотирование корпуса повседневной русской речи «Один речевой день» (ОРД) позволяет увидеть, как говорящий, используя определенные маркеры, выстраивает свою речь, эксплицирует коммуникативные намерения, отношение к адресату, обращается к общей с собеседниками перцептивной базе. Некоторые функциональные единицы буквально отражают структурную сторону речи, делают доступным для анализа сам процесс протекания коммуникации: маркируется начало и конец реплики, вербализуется поиск нужной единиц, опущение (игнорирование) деталей, подчеркивание важного, затруднения разного рода и призыв продолжить коммуникацию. В докладе рассматривается употребление маркеров метакоммуникации в зависимости от социальной роли говорящего. Корпус ОРД имеет обширную метатекстовую разметку, что позволяет анализировать материал с учетом социолингвистических данных и извлекать информацию о коммуникативной ситуации. Социальная роль говорящего является одним из малоизученных параметров в корпусе. Анализ выборки материала, в котором говорящие выступают в социальных ролях, противопоставленных по принципу симметричности/асимметричности отношений, позволил обнаружить некоторую зависимость используемых для построения дискурса единиц метакоммуникации (контактоустанавливающих) от роли говорящего.

Ключевые слова: устная речь, корпус, дискурс, прагматическое аннотирование, прагматические маркеры, метакоммуникация, метакоммуникативы, социальная роль, лингвистические корреляты

Библиографическая ссылка: Попова Т. И. Маркеры метакоммуникации в разных социальных ролях говорящего: на материале прагматического аннотирования корпусных данных // Компьютерная лингвистика и вычислительные онтологии. Выпуск 3 (Труды XXII Международной объединенной научной конференции «Интернет и современное общество», IMS-2019, Санкт-Петербург, 19 - 22 июня 2019 г. Сборник научных трудов). - СПб: Университет ИТМО, 2019. С. 50 - 60. DOI: $10.17586 / 2541-9781-2019-3-50-60$

\section{1. Введение}

В современной лингвистике активно развивается особый подход к изучению бытового диалога как «наиболее нейтрального и наиболее фундаментального вида диалога (conversation(al) analysis; другие переводы этого названия - анализ разговора, анализ речевой коммуникации, конверсационный анализ)» [1]. Диалог рассматривается не только как речевое, но и как социальное взаимодействие, «регулируемое определенными договоренностями между членами общества» [1]. 
Особенно важной в процессе коммуникации становится уверенность говорящих в том, что «код», передаваемый в сообщении, понятен и доступен адресату. «Если говорящему или слушающему необходимо проверить, пользуются ли они одним и тем же кодом, то предметом речи становится сам код: речь выполняет здесь метаязыковую функцию (курив мой - T. П.). Эта функция является неотъемлемой составной функцией любой коммуникации, <..> задачей которой является, например, устранение помех также и в нормальном повседневном разговоре» [2, с. 199]. Помимо этого, с помощью фатической функции языка говорящий имеет возможность проверить, работает ли канал связи, может «привлечь внимание собеседника или убедиться, что он слушает внимательно» [2]. В В. Стрибижев отмечает синонимичность понятий «метакоммуникативная», «контактоустанавливающая» и «фатическая» функции [3].

Отдельные группы единиц, обладающие контактоустанавливающей функцией, рассматривались в некоторых лингвистических исследованиях. Отмечается, что некоторые глаголы, такие как: знаешь / знаете, видишь / видите, понимаешь / понимаете, (по)слушай / (по)слушайте, (по)смотри / (по)смотрите, представь / представьте, способны привлечь внимание адресата к высказыванию (обычно в форме императива или 2 л.) (Сльшь / брат! Ты мне поможешь / я тебе помогу / все люди братья!; Здесь же формуль!! Адски трудно / nосмотри! A?) (подробнее о функциональном своеобразии контактных глаголов см. [4]). Е. А. Гришина ставит подобные единицы в один ряд с частицей ну, текстовым коннектором $a$ и обращениями (Ребят / ну / ну не надо!) и относит к разряду «контактных слов» [5].

Важной представляется также способность метакоммуникативных единиц (ME) выступать в роли так называемых коннекторов, т. е. выполнять интегрирующую функцию. В диалоге смена говорящих ведет за собой и постоянное тематическое варьирование, что иногда приводит к коммуникативным сбоям. В этом случае метатекст, внедряясь в ход диалога, не разрывает структурную целостность, а, скорее, служит ее гарантом. Об этом упоминал Ю. Д. Апресян: «хотя метатекстовые элементы нарушают непосредственное семантическое единство текста, они выполняют интегрирующие функции на высшем уровне, которые перекрывают их разрушительное действие» [6]. Таким образом, «метатекст помогает оформить, “огранить” текст» [7, с. 56].

Такая функциональная характеристика МЕ говорит об их высокой роли в построении дискурса в целом. По своей задаче в построении коммуникации они соотносятся с целыми группами единиц, которые в речи, постепенно утрачивают свое лексическое и грамматическое значение, переходя в разряд функционально нагруженных элементов.

\section{2. Прагматические маркеры устной речи}

Единицы устной речи, которые утрачивают свое непосредственное лексическое и/или грамматическое значение и в процессе повторяющегося речевого употребления начинают выполнять только определенные прагматические функции, получили название прагматических маркеров (ПМ). Это относительно новый термин в современной лингвистике, который был введен в научный обиход Н. В. Богдановой-Бегларян [8]. Назовем некоторые важные для данного исследования отличия прагматических маркеров от дискурсивных (ДМ), под которыми в зарубежной практике понимается очень широкий класс дискурсивных функциональных единиц:

- ПМ употребляются говорящим бессознательно, на уровне речевого автоматизма; ДМ вводятся в текст осознанно, прежде всего с целью его структурирования;

- ПМ не имеют (или имеют ослабленное, почти исчезнувшее) лексическое и/или грамматическое значение; ДМ являются полнозначными единицами устного дискурса;

- ПМ употребляются только (или по большей части) в устной речи; ДМ встречаются как в письменном тексте, так и в устной спонтанной речи; 
- ПМ демонстрируют отношение говорящего к самому процессу порождения речи, вербализуя все затруднения и колебания и являясь зачастую метакоммуникативными единицами; ДМ передают лишь отношение говорящего к тому, о чем он сообщает (см. об этом подробнее: [9], [10], [11], [12]).

Типология прагматических маркеров включает несколько групп: пограничные маркеры, маркеры-аппроксиматоры, маркеры-заместители, маркеры-ксенопоказатели, метакоммуникативные (метакоммуникативы), дейктические, поисковые, рефлексивные, самокорректирующие, ритмообразующие и хезитационные маркеры [8].

Именно с помощью ПМ говорящий эксплицирует свои коммуникативные намерения, отношение к адресату, обращение к общей с собеседниками перцептивной базе.

Благодаря наличию прагматических маркеров, слушающий может воспринять не только содержательную, но и структурную сторону речи, понимает, как протекает коммуникация: - маркируется начало и конец реплики, поиск единиц, опущение (игнорирование) деталей, подчеркивание важного, затруднения разного рода и призыв продолжить коммуникацию.

В настоящем исследовании все единицы с метакоммуникативной функцией будут пониматься как вид прагматических маркеров - метакоммуникативы.

Сбалансированный по ряду социальных параметров говорящих (пол, возраст, уровень образования, профессиональная группа и др.) материал продемонстрировал, какие единицы оказываются наиболее функционально значимыми в устном дискурсе. Ясно, что без метакоммуникативов не может обойтись никакой бытовой диалог.

Важным представляется также рассмотрение материала с точки зрения некоторых социолингвистических параметров, ведь «для использования термина “дискурс" важно представление о включенности коммуникации в социальный контекст» [1].

Стоит отметить, что анализ проведен на сравнительно небольшом материале, что не позволяет считать полученные результаты готовым решением рассматриваемой проблемы.

\section{3. Социальные роли в корпусе ОРД}

Среди многочисленных параметров метатекстового аннотирования корпуса ОРД одним из малоизученных аспектов является категория социальной роли говорящего (CР). Ниже представлен фрагмент классификации СР в ОРД и используемые для их обозначения в базе сокращения (см. рис. 1).

\section{Родственники:}

- МУ - муж,

- ЖЕ - жена

- ОТ - Отец и пр.

Прочие родственники (без

указания пола):

- СР - старшие родственники тетя, свекровь, теща, дядя и пр.

- MP - младшие родственники -

зять, невестка, и пр.

Друзья

• БД- близкий друг (бой-френд)

- БП- близкая подруга (гёрл-

френд)

- ДР/ПО

- АД - ассоциируемый друг (друг друзей, родственников)

\section{Коллеги}

- $\mathrm{KO}$ - коллега

• КН - коллега-начальник, командир

- КД - коллега-друг (подруга) «Парные» отношения

- КЛ - клиент (в том числепокупатель, в транспорте с водителем-кондуктором, на вахте, арендатор квартиры, пациент, родители пациента)

- СС - сервис, сервисная службавсе кто оказывают услугиза деньги (продавец, фотограф, квартирная хозяйка, врач)

CCB - врач

- УЧ - ученик

- ПР - преподаватель, учитель и пр
Группы людей

- СТ - студент(курсант)

- ПI- «попутчик», а также посетитель того же кафе, магазина, поликлиники и пр. общественных мест

Прочее

- ЗН - просто знакомый, не друг, не клиент, не обслуга, не «партнер»

- ЧУ и пр.

Рис. 1. Общая классификация социальных ролей в корпусе ОРД 
Действительно, в процессе общения происходит постоянное речевое переключение, в рамках которого, как представляется, «успех общения в значительной мере зависит от того, в достаточной ли степени владеют говорящий и слушающий формами языка, пригодными для данной ситуации» [13].

Так, владение несколькими кодами проявляется на уровне социальных ролей говорящего, где можно обнаружить специфические черты, или лингвистические корреляты. Социальная роль порождает «ожидание» от человека определенной манеры поведения, в том числе и речевого. В таком случае реализация СР будет варьироваться вместе с ситуацией, но с условием нахождения внутри рамок, допустимых для той или иной роли (подробнее о ролевом наборе в рамках одного «речевого дня» см.: [14]).

\section{4. Материал исследования}

Для анализа были отобраны «речевые дни» двух информантов (И38 - муж., 53 года и И115 - муж., 58 лет), ролевой набор которых равен 8, и у каждого есть эпизоды, в которых информанты выступают в роли как мужа (МУ) при общении с женой, так и службы сервиса (CC) при общении с клиентом. Принцип противопоставленности двух ролей на основании симметричности и асимметричности социальных отношений [15, c. 201-202] должен способствовать выявлению значимых языковых параметров, т. е. искомых лингвистических коррелятов СР. Данные о материале см. в табл. 1.

Таблица 1. Данные о материале

\begin{tabular}{|c|c|c|c|}
\hline Код & Объем подкорпуса (токены ${ }^{\mathbf{1}}$ ) & МУ & СС \\
\hline И38 & 2868 & 1533 & 1335 \\
\hline И115 & 6397 & 2878 & 3519 \\
\hline
\end{tabular}

На первом этапе анализа были составлены частотные списки, верхняя зона которых демонстрирует специфику речи говорящего в той или иной роли [17], [18].

Так, в этой зоне частотного списка И38 удалось обнаружить контактный глагол понимаешь, который служит для привлечения внимания собеседника [4]:

- нет мы ... () понимаешь ... (э) что такое производство вот так сделай / сегодня сегодня три шапки завтра три носка / так не бывает (И38);

— понимаешь (э) тут () всё (э) вот комбинезон это получается (э-э) пять(?) килограмм (И38).

Такое функционирование глаголов в диалоге отсылает к теории вежливости П. Браун и С. Левинсона, описанной в статье «Politeness: Some Universals in Language Usage» [19]. Авторы выделяют категорию социального лица, в том числе связанную с коммуникативным взаимодействием. Человек стремится как принадлежать к сообществу и получать одобрение от членов социума (позитивное лицо), так и обладать свободой и независимостью (негативное лицо).

С этой точки зрения, сама грамматическая форма глагола понимаешь направлена на установление контакта и поддержание позитивного лица собеседника, в то время как императивные формы относятся, скорее, к угрозам негативному лицу слушающего [19, c. $65-68]$.

На основании функциональной активности метакоммуникативов как прагматических маркеров спонтанной речи, что было обнаружено в ходе аннотирования корпусного

\footnotetext{
${ }^{1}$ Токенами в корпусной лингвистике принято называть единицы корпуса - минимальные фрагменты для анализа, хотя чаще всего они совпадают со словоформами [16, с. 159].
} 
материала $^{2}$, и потенциальной возможности определить их как искомые лингвистические корреляты социальных ролей, было принято решение расширить материал, добавив эпизоды из «речевых дней» других информантов, чтобы проанализировать именно явления метакоммуникации.

При этом СР говорящих были другими, но сохранился принцип симметричности / асимметричности отношений (см. рис. 1 со списком сокращений наименования ролей и табл .2).

Таблица 2. Новые эпизоды для прагматической разметки

\begin{tabular}{|l|c|c|c|c|c|c|c|}
\hline Код & Пол & \multirow{2}{*}{ Возраст } & \multicolumn{2}{|c|}{ СР } & \multicolumn{2}{c|}{$\begin{array}{c}\text { Объем подкорпуса } \\
\text { (по ролям) }\end{array}$} & $\begin{array}{c}\text { Объем } \\
\text { подкорпуса }\end{array}$ \\
\cline { 4 - 7 } & & & $\mathbf{X = Y}$ & $\mathbf{X}>/<\mathbf{Y}$ & \multicolumn{2}{|c}{} & \\
\hline И15 & м & 53 & друг & ученик & 746 & 456 & \multirow{2}{*}{16311} \\
\hline И123 & М & 20 & друг & учитель & 2879 & 3980 & \\
\hline И01 & ж & 41 & внучка/друг & клиент & 2217 & 937 & \\
\hline И19 & ж & 33 & мама & коллега & 1469 & 1079 & \\
\hline
\end{tabular}

Таким образом, общий объем исследуемого материала составил 25576 тыс. токенов. Обращает на себя внимание значительная разница объема эпизодов в асимметричных и симметричных отношениях. Только в случае, когда речевая ситуация предполагает, что говорящий выше по положению, как например, учитель (И123), объем подкорпуса изменяется. В основном же все оказываются в положении $\mathrm{X}<\mathrm{Y}$.

\section{5. Результаты}

В случае асимметричных социальных ролей активность метакоммуникативов наблюдается у того говорящего, чей статус «выше» по какому-то параметру (X>Y): служба сервис - клиент, учитель - ученик, доктор - пациент (клиент), командир-кадет:

— пломбировки хвалили? \# да // \# ну так нет просто / ну просто понимаете / вот если б всё от нас зависело / всё б... у вас бы всё было супер (М1 \# И01 \# М1 - врач \# пациент \# врач);

— понятно / почему / да ? три тысячи шестьсот и (э) тут три тысячи шестьсот // понимаешь / что получилось / да ? (И123 - учитель);

- я тебе хочу сказать вот вещь пока не забыл (ИЗ8).

О тесной связи метакоммуникации с отношениями между коммуникантами писали и западные лингвисты: «Мы будем определять метакоммуникацию как все реплики и суждения, которыми обмениваются участники коммуникативного акта, как о (а) коде, так и (б) об отношениях между ними» [22].

Например, особенности выстраивания учебного процесса требуют от педагога умения организовывать взаимодействие. Даже объясняя материал, учитель обращается к слушающему, так происходит контроль кода и активности канала связи:

- ух слушайте / девятьсот // ты говоришь (а) ты пожалуй прав // девяносто третий год / очень трудно (И123).

- Врачу $(\mathrm{X})$ же необходимо создать благоприятную атмосферу в стрессовой для пациента(Y) ситуации:

2. Существуют различные типы аннотаций естественного языка, представленного в корпусе, которые реализуются с помощью различных программ [20]. Однако трудно провести автоматическое аннотирование прагматических маркеров. Прежде всего, это связано с тем, что новый статус единицы реализуют только в контексте, а внешне они ничем не отличаются от значимых единиц. Разметка ПМ в речевом корпусе не является тривиальной и требует значительной ручной работы экспертов-филологов (о путях решения возникающих проблем см.: [12], [21]). 
— старались / ну Люба / тут уже () понимаете // мы сделали / я как бы / *П I'll try ту best (И01 \# М1).

- В то же время говорящему (X) необходимо подчеркнуть авторитетность своего мнения, а для этого нужно привлечь внимание к тому, что он будет говорить или о чем уже сказал:

- просто четвёртый у вас депульпирован / но каналь просто пустые // просто понимаете (И01 \# М1).

Особый интерес в таких случаях представляет сама ситуация употребления метакоммуникативов, ведь можно обнаружить стремление не просто направить слушающего, акцентировать его внимание на каких-то вещах, а желание снять категоричность, обозначить «сближение» в рамках коммуникативной ситуации, которая относится к формальному типу общения.

Выделяются также частные прагматические функции метатекста, такие как портретирование языковой личности и «языковой маски»: говорящий создает свой имидж в том числе и с помощью метапоказателей, иногда намеренно надевая «маску» того или иного типа личности:

- объективного комментатора, используя МЕ объективно говоря;

- открытого и искреннего человека, с помощью МЕ откровенно говоря;

- снижая категоричность, употребляя МЕ мягко говоря [7, р. 57].

Возможно, само стремление создать дружественную атмосферу и преодолеть дистанцию приводит говорящего к использованию прагматических маркеров метакоммуникации. Видны желание позаботиться о своем образе в сознании значимых для говорящего людей и потребность в понимании себя и своего поведения другими людьми.

Например, мама $(\mathrm{X})$ дает дочери (Y) наставления, начиная с маркера привлечения внимания:

— понимаешь / тот кто хочет сделать / он идет и делает / а тот кто ищет оправдания / вот он () он нашел и успокоился (И19).

- Мастер по пошиву гидрокостюмов, прежде чем высказать свое мнение, сообщает о своем намерении что-то сказать:

- слушай ну () в самом деле я хочу тебе сказать что лартек по () сегоднямним рыночным ценам настоящий он безумно дешёвый просто (ИЗ8).

$\mathrm{B}$ то время как собеседник, находящийся в социальной роли $\mathrm{Y}$, использует иные средства для снятия категоричности и демонстрации своего стремления к налаживанию канала и, пожалуй, принятия своей роли:

- вот и(:) (...) чтобы её вернуть / *П и вот (...) я(:) просто хотел завтра / *П чтобы с ребятами собрались спеть ей песню под окном / *П строем (И15 - разговор курсанта с командиром).

Выражение просьбы сопровождается множественными хезитациями, вербальными и невербальными. Маркер вот является частотным в мужской речи маркером хезитативного поиска, кроме того, частотна функция, которую видим в приведенном примере - граница высказывания: начало или конец высказывания, смены темы, своеобразное подведение итогов сказанного. Интересно, что такое неосознанное стремление «сгладить углы» является одним из важных принципов построения речи в риторике, в случае «если аудитория не склонна принимать благожелательно оратора и его мнения или если она плохо подготовлена к восприятию речи» [23, с. 195].

\section{6. Выводы}

Спонтанный бытовой дискурс выстраивается по определенным правилам. Возможно, именно использование специальных маркеров делает речь любого человека доступной для понимания слушающим. Только в случае с риторикой человек имеет возможность готовиться и вносить необходимые исправления, в то время как живое общение требует 
реакции «здесь и сейчас». Вероятно, тогда и начинают работать прагматические маркеры, устойчивые элементы дискурса, которые способны отразить намерения говорящего и наилучшим образом реализовать коммуникативную задачу. Одними из активных участников дискурса являются маркеры-метакоммуникативы. Количественные данные об употреблении прагматических- маркеров в речи говорящих в разных социальных ролях представлены в табл. 3.

Таблица 3. Употребление прагматических маркеров

\begin{tabular}{|c|c|c|c|c|c|c|c|c|c|c|c|}
\hline \multicolumn{2}{|c|}{ И1 } & \multicolumn{2}{|c|}{ И15 } & \multicolumn{2}{|c|}{ И19 } & \multicolumn{2}{|c|}{ И38 } & \multicolumn{2}{|c|}{ И115 } & \multicolumn{2}{|c|}{ И123 } \\
\hline $\mathrm{X}=\mathrm{Y}$ & $X>Y$ & $\mathrm{X}=\mathrm{Y}$ & $X>Y$ & $X=Y$ & $\bar{X}>\mathrm{Y}$ & $\mathrm{X}=\mathrm{Y}$ & $X>Y$ & $\mathrm{X}=\mathrm{Y}$ & $X>Y$ & $\mathrm{X}=\mathrm{Y}$ & $X>Y$ \\
\hline 13 & 4 & 4 & 18 & 5 & 1 & 9 & 35 & 4 & 4 & 15 & 52 \\
\hline \multicolumn{2}{|c|}{ ME } & \multicolumn{2}{|c|}{ ME } & \multicolumn{2}{|c|}{ ME } & \multicolumn{2}{|c|}{ ME } & \multicolumn{2}{|c|}{ ME } & \multicolumn{2}{|c|}{ ME } \\
\hline 3 & нет & 4 & нет & 3 & 1 & 4 & 9 & нет & нет & 4 & 11 \\
\hline
\end{tabular}

Большое количество метакоммуникативов у И123 объясняется спецификой речевой ситуации - идет занятие по математике. Но оно групповое, а не внутри класса, поэтому общение более дружелюбное, что и выстраивается с помощью прагматических маркеров.

Видно, что социальный статус И38 выше, чем у его собеседника, так как он «ведет» клиента по диалогу, в то время как другие информанты, которые выступали в ролевых отношениях как $\mathrm{Y}$, явно не прибегают к использованию маркеров метакоммуникации пациент (И01) или кадет в кабинете командира (И15). Заметнее становится употребление хезитативных ПМ как признак неуверенности, особенно при построении длинных высказываний.

В случаях, когда информанты выступают в симметричных ролевых отношениях, появляется метакоммуникация - общение с друзьями требует наличия постоянного контакта.

Данные о частотности единиц - ipt (на тысячу словоупотреблений) - демонстрируют более высокий показатель употребительности метакоммуникативов в ассиметричных ролях (см. табл.). Важно отметить, что из 6 случаев только в трех встретились МЕ, высокий показатель обусловлен большим количеством МЕ в речи И123 в роли учителя. Таким образом, показатели ipt можно принимать как более близкие друг другу. В таком случае речь идет об активности и функциональной значимости в речи метакоммуникативов в целом.

Таблица 4. IPT маркеров метакоммуникации в подкорпусе

\begin{tabular}{|c|c|c|}
\hline $\begin{array}{c}\text { IPT } \\
\text { (общая) }\end{array}$ & $\begin{array}{c}\text { IPT } \\
(\mathbf{X}=\mathbf{Y})\end{array}$ & $\begin{array}{c}\text { IPT } \\
(\mathbf{X}>\mathbf{Y})\end{array}$ \\
\hline 1,5 & 1,8 & 2,1 \\
\hline
\end{tabular}

Помимо этого, определенный набор ПМ может являться индивидуальным для конкретного говорящего: такая информация может быть использована для выявления диагностических признаков при проведения лингвистической и судебной экспертизы аудиозаписей речевой коммуникации.

Работа выполнена при финансовой поддержке гранта РНФ № 18-18-00242 «Система прагматических маркеров русской повседневной речи» 


\section{Литература}

[1] Кибрик А. А. Диалог // Энциклопедия Кругосвет. URL: https://www.krugosvet.ru/ enc/gumanitarnye_nauki/lingvistika/DIALOG.html (Дата обращения: 23.12.2018).

[2] Якобсон Р. О. Лингвистика и поэтика. Библиографическая информация // Структурализм «за» и «против». - М.: Прогресс, 1975. С. 193-230.

[3] Стрибижев В. В. Речевые клише в современном английском языке: метакоммуникативная функция. Автореф. дис. ... канд. филол. наук. - Белгород, 2005. $-20 \mathrm{c}$.

[4] Маслова Е. Р. Функционирование контактных глагольных форм в русской устной речи. Дис. ... маг. лингв. - СПб., 2016. - 82 с. (машинопись).

[5] Гришина Е. А. О маркерах разговорной речи (предварительное исследование подкорпуса кино в Национальном корпусе русского языка) // Компьютерная лингвистика и интеллектуальные технологии. Труды международной конференции «Диалог 2007» (Бекасово, 30 мая - 3 июня 2007 г.). - М.: РГГУ, 2007. - С. 147-156.

[6] Апресян Ю. Д. Прагматическая информация для толкового словаря // Ю.Д. Апресян. Избранные труды. Т. 2. Интегральное описание языка и системная лексикография. М.: Школа «Языки русской культуры», 1995. С. 629-650.

[7] Перфильева Н. П. Возвращаясь к функциям метатекста // Проблема выбора и интерпретации языкового знака говорящим и слушающим: межвуз. сб. науч. тр. / Под ред. Т. А. Трипольской. - Новосибирск: НГПУ, 2007. С. 51-60.

[8] Богданова-Бегларян Н. В. Прагматемы в устной повседневной речи: определение понятия и общая типология // Вестник Пермского университета. Российская и зарубежная филология. 2014. № 3(27). С. 7-20.

[9] Богданова-Бегларян Н. В. О возможных коммуникативных помехах в межкультурной устной коммуникации // Мир русского слова. 2018. № 3. С. 93-99.

[10] Bogdanova-Beglarian N. V., Filyasova Yu. A. Discourse vs. pragmatic markers: a contrastive terminological study. 5th International Multidisciplinary Scientific Conference on Social Sciences and Arts SGEM2018, Vienna ART Conference Proceedings, 19-21 March 2018. 2018. Vol. 5. P. 123-130.

[11] Bogdanova-Beglarian N., Blinova O., Sherstinova. T., Martynenko G., Zaides K. Pragmatic Markers in Russian Spoken Speech: an Experience of Systematization and Annotation for the Improvement of NLP Tasks // Proceedings of the 23rd Conference of Open Innovations Association FRUCT. Bologna, Italy, 13-16 November. 2018. P. 69-77.

[12] Zaides K. D., Popova T. I., Bogdanova-Beglarian N. V. Pragmatic Markers in the Corpus "One Day of Speech" // Proceedings of Computational Models in Language and Speech Workshop (CMLS 2018) co-located with the 15th TEL International Conference on Computational and Cognitive Linguistics, Kazan. 2018. P. 128-143.

[13] Крысин Л. П. Русское слово, свое и чужое: Исследования по современному русскому и социолингвистике. - М.: Языки славянской культуры, 2004. 888 с.

[14] Попова Т. И. Говорящий вчера, сегодня, завтра, или ролевой набор участника коммуникации // Материалы Международной конференции русистов в Барселонском университете. МКР-Барселона 2018 - Барселона: Барселонский университет. 2018. C. $214-224$.

[15] Беликов В. И., Крысин Л. П. Социолингвистика. - М.: Рос. гос. гум. ун-т, 2001. 315 с.

[16] Baker P., Hardie A., McEnery T. A Glossary of Corpus Linguistics. Edinburgh: Edinburgh University Press, 2006. P. 123.

[17] Попова Т. И. Частотные списки как инструмент поиска лингвистических коррелятов социальных ролей говорящего // Вестник Бурятского государственного университета. Филология. 2018. № 2 (2). С. 33-41. 
[18] Попова Т. И. Параметры частотного словаря в асимметричных и симметричных социальных ролях говорящего // Социо- и психолингвистические исследования. Пермь. 2018. Вып. 6. С. 71-74.

[19] Brown P., Levinson S. Politeness: Some Universals in Language Usage. - Cambridge: Cambridge Univ. Press, 1987. - 358p.

[20] Kuzmenko E. Morphological Analysis for Russian: Integration and Comparison of Taggers / Ignatov D. et al. (eds) // Analysis of Images, Social Networks and Texts. AIST 2016. Communications in Computer and Information Science. Springer, Cham. 2017. Vol. 661. P.162-171.

[21] Bateson G. Information and codification: a philosophical approach / Ruesch J., Bateson G. // Communication: the Social Matrix of Psychiatry. - New Brunswick: Transaction Publishers. 2009. P. 168-211.

[22] Богданова-Бегларян Н. В., Блинова О. В., Мартыненко Г. Я., Шерстинова Т. Ю., Зайдес К. Д., Попова Т. И. Аннотирование прагматических маркеров в русском речевом корпусе: проблемы, поиски, решения, результаты / Гл. ред. В. П. Селегей // Компьютерная лингвистика и интеллектуальные технологии: По материалам ежегодной международной конференции «Диалог» (Москва, 29 мая - 1 июня 2019 г.). 2019. Вып. 18 (25). С. 72-85.

[23] Михальская А. К. Основы риторики: мысль и слово. Учеб. пособие для учащихся 1011 классов. - М: Просвещение, 1996. - 416 с.

\title{
Markers of Metacommunication in Different Social Roles of the Speaker: on the Material of Pragmatic Annotation of Corpus Data
}

\author{
T. Popova
}

\section{Saint Petersburg State University}

Pragmatical annotation of "One Day of Speech " corpus material allows to research communicative intentions of the speaker, his relations with the addressee through the certain speech markers usage during speech construction and appealing to the general for both perceptual database. Some units literally reflect the structural party of the speech, make understandable communication process - marking the beginning and the end of the replics, search of units, omission (ignoring) of the details, underlining difficulties of any kind and an appeal to continue communication.

The paper describes metacommunicative markers usage in its correlation with social role of the speaker. "One Day of Speech" corpus has an extensive metatext markup, which allows to analyze the material from different sides, including sociolinguistic data and information about the communicative situation. The social role of the speaker is one of the little-studied parameters in the corpus. Analysis of a subcorpus in which speakers perform social roles, which are opposed on the principle of the symmetry/asymmetry relations allowed us to discover some dependency of discourse metacommunicative (contact-establishing) units usage from the role of the speaker.

Keywords: colloquial speech, corpus data, discourse, pragmatics, pragmatic markers, pragmatic annotation, metacommunication, metacommunicative markers, social role, linguistic correlates

Reference for citation: Popova T.I. Markers of Metacommunication in Different Social Roles of the Speaker: on the Material of Pragmatic Annotation of Corpus Data // Computer Linguistics and Computing Ontologies. Vol. 3 (Proceedings of the XXII International Joint Scientific Conference «Internet and Modern Society», IMS-2019, St. Petersburg, June 19-22, 2019). St. Petersburg: ITMO University, 2019. P. 50 - 60. DOI: 10.17586/2541-9781-2019-3-50-60 


\section{Reference}

[1] Kibrik A. A. Dialog // Enciklopediya Krugosvet. URL: https://www.krugosvet.ru/ enc/gumanitarnye_nauki/lingvistika/DIALOG.html) (Data obrashcheniya: 23.12.2018).

[2] YAkobson R. O. Lingvistika i poehtika. Bibliograficheskaya informaciya // Strukturalizm «za» i «protiv». - M.: Progress, 1975. P. 193-230.

[3] Stribizhev V. V. Rechevye klishe V sovremennom anglijskom yazyke: metakommunikativnaya funkciya. Avtoref. dis. ... kand. filol. nauk. - Belgorod, 2005. 20 p.

[4] Maslova E. R. Funkcionirovanie kontaktnyh glagol'nyh form v russkoj ustnoj rechi. Dis. ... mag. lingv. - SPb., 2016. 82 p. (mashinopis').

[5] Grishina E. A. O markerah razgovornoj rechi (predvaritel'noe issledovanie podkorpusa kino v Nacional'nom korpuse russkogo yazyka) // Komp'yuternaya lingvistika i intellektual'nye tekhnologii. Trudy mezhdunarodnoj konferencii «Dialog 2007» (Bekasovo, 30 maya - 3 iyunya 2007 g.). - M.: RGGU, 2007. P. 147-156.

[6] Apresyan YU. D. Pragmaticheskaya informaciya dlya tolkovogo slovarya // YU.D. Apresyan. Izbrannye trudy. T. 2. Integral'noe opisanie yazyka i sistemnaya leksikografiya. M.: SHkola «YAzyki russkoj kul'tury», 1995. - P. 629-650.

[7] Perfil'eva N. P. Vozvrashchayas' k funkciyam metateksta // Problema vybora i interpretacii yazykovogo znaka govoryashchim i slushayushchim: mezhvuz. sb. nauch. tr. / Pod red. T. A. Tripol'skoj. - Novosibirsk: NGPU, 2007. - P. 51-60.

[8] Bogdanova-Beglaryan N. V. Pragmatemy v ustnoj povsednevnojrechi: opredelenie ponyatiya i obshchaya tipologiya // Vestnik Permskogo universiteta. Rossijskaya i zarubezhnaya filologiya. 2014. № 3(27). P. 7-20.

[9] Bogdanova-Beglaryan N. V. O vozmozhnyh kommunikativnyh pomekhah v mezhkul'turnoj ustnoj kommunikacii // Mir russkogo slova. 2018. № 3. P. 93-99.

[10] Bogdanova-Beglarian N. V., Filyasova Yu. A. Discourse vs. pragmatic markers: a contrastive terminological study. 5th International Multidisciplinary Scientific Conference on Social Sciences and Arts SGEM2018, SGEM2018 Vienna ART Conference Proceedings, 19-21 March. 2018. Vol. 5. P. 123-130.

[11] Bogdanova-Beglarian N., Blinova O., Sherstinova. T., Martynenko G., Zaides K. Pragmatic Markers in Russian Spoken Speech: an Experience of Systematization and Annotation for the Improvement of NLP Tasks // Proceedings of the 23rd Conference of Open Innovations Association FRUCT. Bologna, Italy, 13-16 November 2018. 2018. P. 69-77.

[12] Zaides K. D., Popova T. I., Bogdanova-Beglarian N. V. Pragmatic Markers in the Corpus "One Day of Speech"// Proceedings of Computational Models in Language and Speech Workshop (CMLS 2018) co-located with the 15th TEL International Conference on Computational and Cognitive Linguistics (TEL 2018), Kazan. 2018. P. 128-143.

[13] Krysin L. P. Russkoe slovo, svoe i chuzhoe: Issledovaniya po sovremennomu russkomu i sociolingvistike. - Moskva: YAzyki slavyanskoj kul'tury, 2004. -888 p.

[14] Popova T. I. Govoryashchij vchera, segodnya, zavtra, ili rolevoj nabor uchastnika kommunikacii // Materialy Mezhdunarodnoj konferencii rusistov v Barselonskom universitete. MKR-Barselona 2018 - Barselona: Barselonskij universitet. 2018. P. 214 224.

[15] Belikov V. I., Krysin L. P. Sociolingvistika. - M.: Ros. gos. gum. un-t, 2001. 315 p.

[16] Baker P., Hardie A. and McEnery T. A Glossary of Corpus Linguistics. Edinburgh: Edinburgh University Press. 2006. 123 p.

[17] Popova T. I. CHastotnye spiski kak instrument poiska lingvisticheskih korrelyatov social'nyh rolej govoryashchego // Vestnik Buryatskogo gosudarstvennogo universiteta. Filologiya. 2018. № 2 (2). P. 33-41.

[18] Popova T. I. Parametry chastotnogo slovarya v asimmetrichnyh i simmetrichnyh social'nyh rolyah govoryashchego // Socio- i psiholingvisticheskie issledovaniya. - Perm. 2018. Vol. 6. P. 71-74. 
[19] Brown P., Levinson S. Politeness: Some Universals in Language Usage. - Cambridge: Cambridge Univ. Press, 1987. - 358p.

[20] Kuzmenko E. Morphological Analysis for Russian: Integration and Comparison of Taggers / Ignatov D. et al. (eds) Analysis of Images, Social Networks and Texts. AIST 2016. Communications in Computer and Information Science, Springer, Cham. 2017. Vol. 661. P.162-171.

[21] Bateson G. Information and codification: a philosophical approach // Ruesch J., Bateson G. Communication: the Social Matrix of Psychiatry. - New Brunswick: Transaction Publishers. 2009. P. 168-211.

[22] Bogdanova-Beglaryan N. V., Blinova O. V. , Martynenko G. YA., SHerstinova T. YU., Zajdes K. D., Popova T. I. Annotirovanie pragmaticheskih markerov v russkom rechevom korpuse: problemy, poiski, resheniya, rezul'taty // Komp'yuternaya lingvistika i intellektual'nye tekhnologii: Po materialam ezhegodnoj mezhdunarodnoj konferencii «Dialog» (Moskva, 29 maya - 1 iyunya 2019 g.). 2019. Vol. 18 (25). P. 72-85.

[23] Mihal'skaya A. K. Osnovy ritoriki: mysl' i slovo. Ucheb. posobie dlya uchashchihsya 10-11 klassov. - M: Prosveshchenie, 1996. - 416 p. 